\title{
Assessing Triggers of Posttrauma Nightmares
}

\section{By}

\section{Westley Atrayeau Youngren}

B.A., The University of Tulsa. 2016

Submitted to the graduate degree program in Clinical Psychology and the Graduate Faculty of the University of Kansas in partial fulfillment of the requirements for the degree of Master of

Arts.

Chair: Nancy A. Hamilton, Ph.D.

Ruth Ann Atchley, Ph.D.

Rick E. Ingram, Ph.D.

Sarah Kirk, Ph.D., ABPP

Date Defended: 23 May 2018 
The thesis committee for Westley A. Youngren certifies that this is the approved version of the following thesis:

Assessing Triggers of Posttrauma Nightmares

Chair: Nancy A. Hamilton, Ph.D.

Date Approved: 23 May 2018 


\begin{abstract}
Introduction: Posttrauma nightmares are highly problematic and treatment resistant symptoms that can occur after an individual experiences a traumatic event. Posttrauma nightmares can occur as frequently as 4-6 times per week, but often occur in a seemingly random pattern. Although these parasomnias are quite prevalent in trauma survivors, very little is known about the mechanisms underlying their sporadic occurrence. Thus, the purpose of this study was to investigate potential triggers of posttrauma nightmares.
\end{abstract}

Methods: The current study consisted of 27 female college students who reported frequently experiencing posttrauma nightmares related to a sexual trauma. Approximately half of the sample was recruited from an introduction to psychology participant pool and half from clinical referrals. Participants completed an initial assessment battery as well as 6 consecutive days of pre and postsleep diaries, which included measures of potential triggers of posttrauma nightmares as well as measures intended to assess sleep quality and posttrauma nightmare occurrence. Descriptive statistics, mean comparison analyses, mixed effects logistical regressions, and moderation analyses were used to examine the data.

Results: Overall, the sample consisted of high levels of general psychopathology and 28 posttrauma nightmares were reported. Results suggest that presleep cognitive arousal and sleep latency both predict the occurrence of posttrauma nightmares. Further, moderation results suggest that presleep cognitive arousal moderates the relationship between sleep latency and posttrauma nightmare occurrence.

Conclusion: Overall, the results of this study are the first to report that presleep cognitive arousal and sleep latency, both individually and combined may influence the occurrence of a posttrauma nightmare. 


\section{Table of Contents}

I. Introduction
a. Posttraumatic Stress Disorder (PTSD)
b. Posttraumma Nightmares
c. Posttraumma Nightmare Triggers
d. Summary and Hypotheses

II. Methods
a. Participants
b. Procedure
c. Analyses

III. Results

IV. Conclusion
a. Sleep Latency
b. Presleep Cognitive Arousal
c. Moderation
d. Limitations and Future Directions
e. Summary and Clinical Implications

\section{References}

VI. Tables

VII. Figure 


\section{Assessing Triggers of Posttrauma Nightmares}

It is estimated that around 20-25\% of women will experience some form of a sexual trauma during their time in college (Lindquist, Warner, Fisher, \& Martin, 2009). In tangible numbers this means that out of the 11.6 million females who will attend college in the United States in 2016, 2.3 million women will be, or have experienced a sexual trauma during their time in college (U.S. Department of Education, National Center for Education Statistics, Common Core of Data CCD, 2016). Although sexual trauma is common among college aged women, there is actually very little research focused on Post Traumatic Stress Disorder (PTSD) symptoms, specifically posttrauma nightmares (reoccurring nightmares that begins after a trauma; Hartmann, 1984), in women on a college campus who have experienced a form of sexual assault. Posttrauma nightmares may be particularly common in this population because women have been found to be more vulnerable to sleep disorders than men (Hiestand, Britz, Goldman, \& Phillips, 2006). In order to answer these voids in the literature, this study aims to investigate the triggers of posttrauma nightmares in a sample of college women who have been sexually assaulted.

\section{Posttraumatic Stress Disorder}

Posttraumatic Stress Disorder (PTSD) is a psychological disorder that can develop after an individual experiences, witnesses, or learns about, a traumatic event (American Psychiatric Association, 2013). The DSM-5 reports that approximately 3-5\% percent of individuals living in the U.S. will experience PTSD in their lifetime (American Psychiatric Association, 2013). This prevalence rate is much higher in certain populations, such as male combat veterans $(\sim 23 \%$ of male combat veterans suffer from posttraumatic stress disorder; Brancu et al., 2016). In addition to combat veterans, PTSD is also highly prevalent in sexual trauma survivors. In fact, research 
has suggested that around $47-94 \%$ of women who experience a sexual trauma will experience PTSD symptoms immediately following the trauma (Rothbaum, Foa, Riggs, Murdock, \& Walsh, 1992). Thus, given that the most common prevalence rate suggests that approximately $20-25 \%$ of female college students will experience a sexual trauma during college (Fedina, Holmes, \& Backes, 2018), PTSD symptoms may also be especially prevalent among female college students.

Despite the high prevalence of sexual assault and PTSD among sexual assault survivors, the preponderance of research on the psychological costs of PTSD has focused on male combat veterans. For example, recent research suggested that PTSD may be linked to the recent spike in suicide within the veteran population (Jakupcak, Hoerster, Varra, Vannoy, Felker, \& Hunt, 2011). Furthermore, research has linked PTSD to several other negative outcomes such as depressions, anxiety, substance abuse, and several sleep disorders (Campbell, Felker, Liu, Yano, Kirchner, Chan, \& Chaney, 2007; Kilpatrick, Ruggiero, Acierno, Saunders, Resnick, \& Best, 2003; Lamarche \& De Koninck, 2007). Although there is a wealth of research on PTSD, one of the remaining enigmatic symptoms is the posttrauma nightmare.

\section{Posttrauma Nightmares}

One of the most problematic outcomes of PTSD is the posttrauma nightmare, which is a symptom of the PTSD Intrusion cluster (American Psychiatric Association, 2013). An idiopathic nightmare has been commonly defined as a bad dream that awakens the dreamer and is

remembered upon awakening. In contrast, posttrauma nightmares has been commonly defined as reoccurring nightmares (bad dream that awakens the dreamer) that begin after a triggering trauma (Hartmann, 1984). Posttrauma nightmares occur so frequently with PTSD, that they have been described as a universal symptom and hallmark trait of PTSD (Germain, 2013). In fact, 
prevalence rates of posttrauma nightmares in trauma survivors has been reported as high as $88 \%$ (Forbes, Phelps, \&McHugh, 2001; Ohayon, \& Shapiro, 2000).

Other than being quite prevalent in trauma survivors, posttrauma nightmares are also highly problematic. In addition to being highly distressing in and of themselves (frequently being exact replicas of a traumatic event), posttrauma nightmares often result in sleep loss because it is often impossible to return to sleep following the nightmare. Relatedly, posttrauma nightmares have been linked to insomnia, as well as comorbidities including depression, anxiety, cardiovascular risk factors, alcohol abuse, suicidal ideations, and suicide attempts (GalatzerLevy, Nickerson, Litz, \& Marmar, 2013; Nadorff, Nazem, \& Fiske, 2013; Pacella, Hruska, \& Delahanty, 2013; Van der Kolk, Blitz, Burr, Sherry, \& Hartmann, 1984). Unfortunately, research suggests that they are exceptionally hard to treat and often persist after all other symptoms of PTSD have remitted (Pruiksma, Taylor, Wachen, Mintz, Young-McCaughan, Peterson, \& Resick, 2016). Although posttrauma nightmare literature is evolving, there are still notable gaps in the literature.

As of today, the majority of posttrauma nightmare research has primarily focused on male combat veterans. Very little research has examined posttrauma nightmares among college female sexual assault survivors. College aged women may be especially vulnerable to posttrauma nightmares given the rates of sexual assault in college and because women experience sleep disorders more frequently than men (Hiestand, Britz, Goldman, \& Phillips, 2006). Therefore, the primary goal of this study was to expand the posttrauma nightmare literature by investigating a population that is heavily under researched, female college students who have experienced a sexual trauma.

\section{Posttrauma Nightmare Triggers}


While little is known about posttrauma nightmares in specific populations, even less is known about what triggers the occurrence of a posttrauma nightmare. Posttrauma nightmares can occur as frequently as 3-4 times per week (usually not on consecutive nights; Davis, 2008). Although this sporadic occurrence is recognized, very little research has attempted to identify why these nightmares occur on some nights instead of others. In fact, to date, no study has been specifically designed identify triggers of posttrauma nightmares. The following paragraphs review a likely set of predictors of posttrauma nightmares derived from both trauma and sleep research.

Reminiscent stimuli. The extant literature's best, and most commonly stated explanation for posttrauma nightmares is that reminiscent stimuli trigger the occurrence of posttrauma nightmares (Hartmann, 1984). Reminiscent stimuli are experiences that remind an individual of the trauma that has caused the nightmares (the triggering trauma). Stimuli that remind an individual of the triggering trauma are the most commonly understood predictors of flashbacks and unwanted memories (Michael, Ehlers, Halligan, \& Clark, 2005). If posttrauma nightmares are related to other PTSD intrusion symptoms such as flashbacks, then it is plausible to suggest that reminiscent stimuli that trigger flashbacks may also trigger nightmares. It should be noted however, that the link between these predictors and posttrauma nightmares is based on the assumption that posttraumatic nightmares are similar to other intrusion symptoms like flashbacks (Ehlers, Hackmann, \& Michael, 2004). However, there is no empirical literature to support this assumption.

If indeed reminiscent stimuli predict posttrauma nightmares, it is possible that the effect may be influenced by cognitive or physiological arousal. Research has found that reminiscent stimuli can lead to increased arousal (Center for Substance Abuse Treatment, 2014). If arousal 
persists until bedtime, it is possible that arousal is the more proximal cue for posttrauma nightmares.

Pre-sleep arousal. Autonomic nervous system arousal has been directly linked to insomnia symptoms (Bonnet \& Arand, 2010), as well as the occurrence of posttrauma nightmares (Hartmann, 1984). Levin \& Nielsen (2007) have proposed a model suggesting that increased arousal (via the HPA-Axis) may play a pivotal role in producing non-trauma nightmares. Thus, if arousal is connected to the manifestation of nightmares, it may follow that pre-sleep arousal may predict the occurrence of a posttrauma nightmare. Relatedly, Prazosin, the leading medication for preventing nightmares, is an alpha-blocker originally created to treat high blood-pressure (Raskind, Peskind, Kanter, Petrie, Radant, Thompson, \& Thomas, 2003). Therefore, if a medication that decreases autonomic arousal also reduces the likelihood of experiencing a posttrauma nightmare, then it is possible that increased arousal may predict the occurrence of a nightmare.

Given that cognitive arousal is a psychological manifestation of physiological arousal (via the HPA-Axis; Thayer, 1990), it follows that presleep cognitive arousal may also increase the chance of a posttrauma nightmare occurrence. This aligns with a large amount of existent literature that suggests presleep arousal (in the forms of worry and rumination) can negatively impact an individual's sleep quality, by increasing sleep latency and decreasing subjective sleep quality (Borders, Rothman, \& McAndrew, 2015; Smith, Perlis, Carmody, Smith, \& Giles, 2001). Further, rumination of a past traumatic event has been found to predict the maintenance of PTSD symptom severity (Ehring, Frank, \& Ehlers, 2008). Thus, given that presleep cognitive arousal is produced by physiological arousal and given that it may impact both sleep and PTSD symptom severity, it is possible that it may also influence the manifestation of a posttrauma nightmare. 
Sleep quality \& fatigue. Poor sleep quality and fatigue may also potentially trigger the occurrence of a posttrauma nightmare. Research suggests that bad dreams (distressing dreams that don't awaken the dreamer) and nightmares occur during both REM and Non-REM sleep. Individuals experiencing poor sleep quality or sleep deprivation, both of which are highly related to posttrauma nightmares (Spoormaker, Schredl, \& van den Bout, 2006) accumulate sleep debt, which may result in REM and Slow Wave Sleep (SWS) rebound. Rebound sleep is characterized by increased proportions of REM and SWS (Rechtschaffen, Bergmann, Gilliland, \& Bauer, 1999; Roehrs, Hyde, Blaisdell, Greenwald, \& Roth, 2006). Thus, if an individual is more likely to spend time in a stage of sleep where nightmares are known to occur (i.e., REM \& non-REM), it may increase their likelihood of experiencing a posttrauma nightmare. In addition to a direct effect, poor sleep quality and fatigue may decrease one's ability to regulate and process their emotions during the day (Kerkhof \& Van Dongen, 2010; Stickgold, Hobson, Fosse, \& Fosse, 2001). Poor emotional regulation has also been linked to Posttrauma Nightmare frequency (Levin \& Nielsen, 2007; Spoormaker, Schredl, \& van den Bout, 2006). If the latter is true, then the reciprocal relationship between posttrauma-nightmares and fatigue/sleep deprivation may offer an explanation for why posttrauma nightmares persist despite successful treatment of other PTSD symptoms.

Stress. Individuals suffering from frequent nightmares report high levels of chronic stress (Davis, 2008). More importantly, pre-sleep stress has been found to predict idiopathic nightmares and bad dreams (Morrison, 1989). In fact, pre-sleep stress so commonly produces bad dreams, these bad dreams have received their own name, stress dreams. It should also be noted that some researchers believe bad dreams, stress dreams, and nightmares to be very closely 
related (Hartmann, 1998). Thus, if stress predicts the occurrence of bad dreams and stress dreams, then it may also predict the occurrence of posttrauma nightmares.

\section{Summary and Hypotheses}

In sum, posttrauma nightmare research in sexual assault survivors is sparse, especially in the specific population of college women. Additionally, posttrauma nightmare research has yet to establish concrete links between potential triggers and the occurrence of posttrauma nightmares. Therefore, in order to answer these voids, this study utilized daily and nightly sleep diaries to identify the triggers of Posttrauma Nightmares in a sample of college women who reported experiencing a sexual trauma. Given that postrauma nightmares are classified as an intrusion symptom, we assessed daily reports of reminiscent stimuli. However, our list of candidate literature was also informed by research on parasomnias. Thus, our list of candidate triggers also included reports of presleep arousal, poor sleep quality, fatigue, and stress. Using this panel of putative nightmare triggers, the following hypotheses were tested:

Hypothesis 1: Experiencing reminiscent stimuli will predict the occurrence of posttrauma nightmares.

Hypothesis 2: Poor sleep quality will predict the occurrence of posttrauma nightmares. Hypothesis 3: High levels offatigue will predict the occurrence of posttrauma nightmares.

Hypothesis 4: High levels of pre-sleep arousal will predict the occurrence of posttrauma nightmares.

Hypothesis 5: High levels of perceived stress will predict the occurrence of posttrauma nightmares.

\section{Methods}




\section{Participants}

Participants were recruited through two different methods. The first method used to recruit participants was part of a larger study, Prevalence of Traumatic Experiences on Campus (POTEC). POTEC gathered information about the prevalence of traumatic experiences and posttrauma nightmares from a sample of students enrolled in an Introduction to Psychology

class. POTEC was one of a large number of studies available to students as partial fulfillment of a course assignment during the 2016-2017 academic year. As part of the POTEC questionnaire battery, student participants were given the option to consent to be contacted for future research. Interested participants who met initial study criteria and consented to be contacted for future research were contacted by email by for potential participation.

The second method used to recruit participants was by referral from community mental health care provider. Female clients seeking treatment for posttrauma symptoms caused by a sexual trauma were given the research coordinator's email address and study information. Interested potential study participants contacted the research coordinator and set up a time to determine participation eligibility and enrollment.

Inclusionary criteria were a) self-reported experience of a sexual trauma b) experiencing nightmares related to a sexual trauma and c) self-reporting as a female. No participants reported suicidal, self-harm, or homicidal ideation. If that had happened, the participants would have been unenrolled from the study and the appropriate measures to ensure safety would have been implemented. Participants were not compensated financially for their time. A complete list of the recruitment procedure can be seen in Diagram 1. All of the study's protocols were approved by the University of Kansas' Institutional Review Board. 
A total of 1,089 participants responded to the POTEC survey, of which 677 identified as female. The demographics of this sample were consistent with the expected demographics of a first year college student class, with a mean age of $M=19.13(S D=2.38)$. Within this unselected sample of college students, $4.73 \%(n=32)$ were females who reported experiencing nightmares related to a sexual trauma and were willing to be contacted for future research. Out of this sample $(N=32)$, all were contacted for potential participation and $35.89 \%(n=14)$ agreed to participate. Participants recruited from community mental health clinics were recruited from a population of unknown size. However, of the 16 who initiated contact with this project, $100 \%$ agreed to participate.

\section{Procedure}

Participants agreeing to participate in the study completed an informed consent form that explained the purpose and procedure of the study. Immediately following the completion of the informed consent form, a trained clinical researcher administered the PTSD module of the semistructured clinical interview for the DSM-V (SCID-V; First, Williams, Karg, \& Spitzer, 2015) as well as a battery of questionnaires used to assess general depression and anxiety related psychopathology. Participants were then instructed to complete evening (presleep) and morning (postsleep) electronic sleep/dream diaries for the next consecutive six days. Participants accessed these diaries from a reusable link emailed to their personal email account and completed the questionnaires with their personal electronic devices. When the participants finished the study, they were thanked for their time, and debriefed (which included a summary of their reported sleeping patterns throughout the study).

\section{Baseline Measures}


PTSD symptomatology was assessed via the PTSD module from the Structured Clinical Interview for the DSM-V (SCID-V; First, Williams, Karg, \& Spitzer, 2015). The SCID was also used to assess for suicidal ideations. In addition to the SCID-V, the Beck Depression Inventory-I (BDI-I; Beck, Steer, \& Brown, 1996) and Beck Anxiety Inventory (BAI; Beck, Epstein, Brown, \& Steer, 1988) were used to assess depression and anxiety related symptoms. The SCID-V, BDI, and BAI are highly validated measures of psychopathology, depression, and anxiety symptoms $(r$ $=.75 ; r=.86 ; r=.67 ;$ Forbes, Phelps, \& McHugh, 2001; Wang \& Gorenstein, 2013).

\section{Presleep Diaries.}

Presleep diaries included daily assessments of putative daytime predictors of nightmares including reminiscent stimuli, presleep arousal, perceived stress, and fatigue. Participants were told to complete these measures immediately before going to bed.

Reminiscent Stimuli. To assess whether or not a participant experienced an event that reminded them of the triggering trauma, participants were asked the following close ended question, "did you experience any event today that reminded you of the trauma associated with

your nightmares? This event could have been, but is not limited to, visual reminders, people, places, sounds, smells, thoughts, feelings, life events or anniversaries" If the participant endorsed experiencing a reminiscent stimulus, she was then asked to describe the stimuli (open ended question). There are no empirically validated measures of nightmare triggers. Thus, this question was generated specifically for this study and has no psychometric data.

Non-nightmare intrusion symptoms. To assess the occurrence of other non-nightmare intrusion symptoms (flashbacks and unwanted memories), two question from the PTSD Checklist 5 (PCL-5, Weathers, Litz, Keane, Palmieri, Marx, \& Schnurr, 2013) were inserted into the nightly survey. These questions were, "today did you experience disturbing and unwanted 
memories of the traumatic experience" and "today did you suddenly feel or act as if the stressful experience were actually happening again (as if you were actually back there reliving it)?"

Participants responded with either yes, no, or unsure. If a participant endorsed experiencing one of these intrusion symptoms (yes), they were then asked how many times this experience happened during the day. The PCL-5 has been found to be a reliable $(\alpha=.82 ;)$ and valid $(r=.85$; Blevins, Weathers, Davis, Witte, \& Domino, 2015) tool for assessing PTSD symptoms, such as flashbacks and unwanted memories.

Pre-sleep arousal. The Pre-Sleep Arousal scale is a 16-item scale that assesses somatic and cognitive pre-sleep arousal states. Participants responded on a scale ranging from, 1 (not at all) to 5 (extremely). Higher scores indicated higher states of pre-sleep arousal (Nicassio, Mendlowitz, Fussell, \& Petras, 1985). The subscales of the Pre-Sleep Arousal scale have been found to be a reliable (somatic, $\alpha=.79, \&$ cognitive, $\alpha=.88$ ) and valid $(r=.58$; Nicassio, Mendlowitz, Fussell, \& Petras, 1985) measurement of arousal prior to sleep.

Perceived stress. The Perceived Stress Scale (PSS: Cohen, Kamarck, \& Mermelstein 1983) is a 14-item scale intended to assess the amount of perceived stress experienced in the past month. The scale was edited to capture perceived stress experienced during the day. Participants respond with a scale ranging from, 0 (never) to 4 (very often). Higher scores represented higher levels of perceived stress during the preceding day. This scale has been found to be a reliable ( $\alpha$ $=.84)$ and valid $(r=.65$; Cohen, Kamarck, \& Mermelstein, 1983) measurement of perceived stress.

Fatigue. The Fatigue Assessment Scale (FAS: Michielsen, De Vries, \& Van Heck 2003) is a 10-item scale intended to assess physical, mental, and motivational fatigue. Participants responded with a scale ranging from, 1 (never) to 5 (always). Higher scores represent higher 
levels of perceived fatigue. This scale has been found to be a reliable $(\alpha=.90)$ and valid $(r=$

.78; Michielsen, De Vries, \& Van Heck, 2003) measurement of fatigue.

Postsleep Diaries.

Postsleep diaries included assessments of sleep quality and also questions about dreaming. Participants completed these measures as soon as possible after they awoke.

Sleep quality. The PSQI (Buysse, Reynolds, Monk, Berman, \& Kupfer, 1989) was used to measure sleep quality. The PSQI instructions were edited to capture the previous night's sleep. The PSQI is a 9-item scale that measures overall sleep quality and the following 7 subscales; subjective sleep quality, sleep latency, sleep duration, sleep efficiency, sleep disturbances, use of sleep medications, and daytime dysfunction. The PSQI (Buysse, Reynolds, Monk, Berman, \& Kupfer, 1989) has been found to be a reliable $(\alpha=.08 ;)$ and valid $(r=.69$; Carpenter \& Andrykowski, 1998) tool for assessing sleep quality. To avoid complications of covariance, the PSQI \#5h question was removed from the administration of the PSQI during this study. The PSQI \#5h assessed for bad dreams as a cause of sleep disruption.

Nightmares \& dreams. To capture the occurrence of nightmares and to ensure we were assessing posttrauma nightmares and not another type of dream, a nightmare \& dream scale was created for this study. This scale assessed types of dreams and emotions associated with the endorsed dreams. The participants were first asked if they remembered their dreams last night and $(\mathrm{Y}, \mathrm{N})$. If they answered $\mathrm{Y}$, they were asked if one of their dreams was a bad dream (nightmare) that woke them from their sleep and was related to their triggering trauma (Y, N). If they answered Y to this question, they were asked to write the content of that dream; if they answered $\mathrm{N}$ to this question, they were asked to categorize their most well remembered dream. Other dream categories were include: bad dreams that woke the dreamer but were NOT related 
to the triggering trauma, bad dreams that didn't wake the dreamer, stress dreams, vivid dreams, bizarre dreams, emotional dreams, joyful dreams, and neutral dreams. If the participant endorsed any of these dreams they were then asked if the dream was related to the triggering trauma. Additionally, if the participant endorsed experiencing a dream or a posttrauma nightmare, they were also asked to select an emotional valence associated with that dream/nightmare (either, "positive" or "negative") and an emotional arousal state associated with that dream/nightmare (either "high" or "low"). If the participant endorsed "don't remember my dream's content" they were still asked to select an emotion that was related to the non-remembered dream (same emotion scale as earlier, but with an additional option "don't remember"). The participant was then asked if they remembered any other dreams $(\mathrm{Y}, \mathrm{N})$. If the participant selected $\mathrm{N}$, the measure was concluded. If the participant selected $\mathrm{Y}$, the scale would start again from the beginning.

This scale was designed specifically for this study, so no data exists on its validity and reliability. However, the dream type scale was constructed similarly other existing dream scales based on recommendations from Schneider \& Domhoff (2001). The nightmare assessment portion was similar to the Trauma Related Nightmare Scale (Davis, Wright, \& Borntrager, 2001), which is a larger scale intended to assess posttrauma nightmares. The emotional assessment portion of this scale was constructed to capture the four quadrants of emotions, defined by the emotional circumplex (arousal \& valence; Feldman, 1995).

\section{Analyses}

All analyses were conducted with $R$ statistical software version 3.4.4 and IBM SPSS Statistics 23. For descriptive statistics, Mean, Median, and Mode analyses were conducted. 
Prevalence statistics were also conducted. Cronbach's Alpha's were used to measure the internal reliability of applicable measures.

Given that nights were clustered within persons, $R$ 's generalized linear model command (glmer) was used to estimate a series of mixed effects logistic regression models with presleep somatic arousal (PSA), presleep cognitive arousal (PCA), sleep quality (SQ), subjective sleep quality (SSQ), sleep latency (SL), sleep duration (SD), sleep efficiency (SS), daytime dysfunction (DD), fatigue (FTG), and stress (STRS) as participant level continuous predictors and reminiscent stimuli (REMSTEM) as a participant level categorical predictor of posttrauma nightmare occurrence, with participant number (PN) and temporal assessment period (time) as the repeated measure random effects. In attempt to minimize the possibility of type- 2 error, individual analyses were conducted instead of one single equation. In each equation the occurrence of a nightmare by person $(i)$ was predicted by individual predictors controlling for time $(j)$. The following equations were utilized:

$$
\begin{aligned}
& \log \left[X_{i j}\right]=\beta 0_{j}+\beta 1_{j} * t_{i m e} e_{i j}+\beta 2 * P S A_{i j}+\varepsilon_{i j} ; \beta 0_{j}=y 00+M 0_{j} ; \beta_{i j}=y 10+M_{i j} \\
& \log \left[X_{i j}\right]=\beta 0_{j}+\beta 1_{j} * t_{i m e} i j+\beta 3 * P C A_{i j}+\varepsilon_{i j} ; \beta 0_{j}=y 00+M 0_{j} ; \beta_{i j}=y 10+M_{i j} \\
& \log \left[X_{i j}\right]=\beta 0_{j}+\beta 1_{j} * t i m e_{i j}+\beta 4 * S Q_{i j}+\varepsilon_{i j} ; \beta 0_{j}=y 00+M 0_{j} ; \beta_{i j}=y 10+M_{i j} \\
& \log \left[X_{i j}\right]=\beta 0_{j}+\beta 5_{j} * t_{i m e} e_{i j}+\beta 2 * S S Q_{i j}+\varepsilon_{i j} ; \beta 0_{j}=y O 0+M 0_{j} ; \beta_{i j}=y 10+M_{i j} \\
& \log \left[X_{i j}\right]=\beta 0_{j}+\beta 1_{j} * t i m e_{i j}+\beta 6^{*} S L_{i j}+\varepsilon_{i j} ; \beta 0_{j}=y 00+M 0_{j} ; \beta_{i j}=y 10+M_{i j} \\
& \log \left[X_{i j}\right]=\beta 0_{j}+\beta 1_{j} * t i m e_{i j}+\beta 7^{*} S D_{i j}+\varepsilon_{i j} ; \beta 0_{j}=y 00+M 0_{j} ; \beta_{i j}=y 10+M_{i j} \\
& \log \left[X_{i j}\right]=\beta 0_{j}+\beta 1_{j} * t i m e_{i j}+\beta 8 * S S_{i j}+\varepsilon_{i j} ; \beta 0_{j}=y 00+M 0_{j} ; \beta_{i j}=y 10+M_{i j} \\
& \log \left[X_{i j}\right]=\beta 0_{j}+\beta 1_{j} * t i m e_{i j}+\beta 9^{*} D D_{i j}+\varepsilon_{i j} ; \beta 0_{j}=y 00+M 0_{j} ; \beta_{i j}=y 10+M_{i j}
\end{aligned}
$$




$$
\begin{aligned}
& \log \left[X_{i j}\right]=\beta 0_{j}+\beta 1_{j} * \text { time }_{i j}+\beta 10^{*} F T G_{i j}+\varepsilon_{i j} ; \beta 0_{j}=y 00+M 0_{j} ; \beta_{i j}=y 10+M_{i j} \\
& \log \left[X_{i j}\right]=\beta 0_{j}+\beta 1_{j} * t_{i m e_{i j}}+\beta 11^{*} S T R S_{i j}+\varepsilon_{i j} ; \beta 0_{j}=y 00+M 0_{j} ; \beta_{i j}=y 10+M_{i j} \\
& \log \left[X_{i j}\right]=\beta 0_{j}+\beta 1_{j} * \text { time }_{i j}+\beta 12^{*} \text { REMSTEM } \\
& \left.i j+\varepsilon_{i j} ; \beta 0_{j}=y 00+M 0_{j} ; \beta_{i j}=y 10+M_{i j}\right)
\end{aligned}
$$

Estimates are based on an adaptive Gaussian Hermite approximation of the likelihood, in particular with 10 integration points. A different optimizer was specified in order to avoid nonconvergence.

The analytic strategy used in all mixed effects logistic models was as follows. Consistent with the study hypotheses all first order relationships were examined using individual logistic regression equations. Following these planned analyses, post-hoc moderation analyses were used to examine the moderating effect of presleep cognitive arousal on the relationship between sleep latency and posttrauma nightmare occurrence. Prior research has suggested cognitive arousal, such a sleep apprehension, sleep anxiety, and rumination can increase the time it takes to fall asleep (sleep latency; Wicklow \& Espie, 2000; Zoccola, Dickerson, \& Lam, 2009). To test for potential moderating relationships, the Process Macro was used (Hayes, 2012). The Process Macro (Hayes, 2012) utilizes mixed effects analyses, logistical hierarchical regressions, and an interaction term to examine the indirect effect of presleep cognitive arousal on the relationship between sleep latency and nightmare occurrence.

\section{Results}

\section{Participants}

The sample included $N=27$ female college students who reported experiencing nightmares related to a sexual trauma. The median age for the sample was, $M=20.05(S D=$ 3.08). The sample consisted primarily of white $(n=16 ; 59.26 \%)$ females who reported an 
average family income ranging from $\$ 30,000-75,000$ annually. About half of participants in both the clinical and POTEC samples reported past traumas as well as past sexual traumas. The vast majority of the sample met criteria for a PTSD diagnosis $(N=25 ; 92.6 \%)$. In general, there were few differences between recruitment groups (clinical referral and POTEC), with both groups reporting similar levels of past trauma prevalence, PTSD symptom severity, and distressed sleep. In fact, both groups exceeded the PSQI cutoff score for clinically distressed sleep (>5; Buysse et al, 1989), but were not statistically different from each other.

Although the two groups were similar with regards to demographic variables, there were some differences. For example, the clinical sample reported significantly higher levels of depression and anxiety related symptoms. In fact, the clinical sample's mean scores for anxiety symptoms were above the minimum severe cutoff score $(\geq 26$; Beck, Epstein, Brown, \& Steer, $1988)$ and their depression symptoms were above the minimum moderate cutoff score $(\geq 20$; Beck, Steer, \& Brown, 1996), suggesting high levels of psychological distress. Although the clinical sample's scores for anxiety and depression were significantly higher than the POTEC sample's scores, the POTEC sample also reported elevated anxiety and depression scores, both above the minimum moderate range cutoff score (BAI $\geq 16$; BDI $\geq 20$ ), which suggests that both samples were experiencing elevated levels of psychological distress. Other than anxiety and depression, the other significant differences were that the clinical sample reported higher levels of fatigue, higher levels of daytime dysfunction, that they were at a younger age when they experienced the trauma the triggered their posttrauma nightmares, and that they experienced reminiscent stimuli more frequently than the POTEC sample. For more information, Table $1 \&$ and Table 2 report all participant characteristics and predictor descriptives, combined and stratified by recruitment method. For recruitment, retention and adherence, see Figure 1. 


\section{Retention \& adherence}

In total, thirty participants completed the informed consent process for this study. Two participants did not adhere to the study protocol and were removed from analyses. One participant was diagnosed with Narcolepsy. Because she was heavily medicated for narcolepsy and experienced frequent hypnogogic hallucinations, she was removed from data analyses. Seven participants completed less than six, but more than two continuous pre and postsleep surveys. Following mixed model missing data recommendations by (Faraway, 2016), these participants remained in analyses. The remaining participants $(N=20)$ completed at least six consecutive pre and post sleep surveys.

\section{Assessment Reliability}

Observed internal consistency reliability for all established psychometric instruments was similar to published norms. These data are presented in Table 3.

\section{Posttrauma Nightmare Occurrence}

During the course of the study, 30 posttrauma nightmares were reported. Overall, 5 participants $($ POTEC $=3$; Clinical $=2$ ) did not report experiencing a posttrauma nightmare while enrolled in the study, 15 participants $(\mathrm{POTEC}=6$; Clinical $=9)$ reported experiencing 1 posttrauma nightmare while enrolled in the study, 6 participants $($ POTEC $=3$; Clinical $=3$ ) reported experiencing 2 posttrauma nightmares while enrolled in the study, and 1 participant (Clinical) reported experiencing 3 posttrauma nightmares while enrolled in the study. On average, participants experienced 1.07 posttrauma nightmares. Participants in the clinical sample reported experiencing more nightmares $(M=1.26, S D=0.41)$ than the POTEC sample $(M=$ $0.88, S D=0.34)$. However, this difference was not statistically significant. The average time of posttrauma nightmare occurrence was 3 hours and 35 minutes after falling asleep (215.04 
minutes). The average sleep onset latency time (SOL) on nights when posttrauma nightmares occurred was 62.4 minutes, which was significantly higher than on nights when posttrauma nightmares did not occur (30.3 minutes; $p<.01)$. The average total sleep time (TST) on nights when posttrauma nightmares occurred was 388.85 minutes, which was significantly less than on nights when posttrauma nightmares did not occur (462.63 minutes, $p<.01)$. Presented in Table $4 \mathrm{a}$ and $4 \mathrm{~b}$ are the descriptive statistics for each IV stratified by the occurrence of a posttrauma nightmare. In order to statistically compare predictors by nightmare occurrence, predictor data were aggregated within person and compared between groups, using paired t-tests and chi-square analyses.

\section{Predictors of posttrauma nightmare occurrence}

Results of the mixed effects logistic regressions showed that sleep latency (SL; $B=0.76$, $p<.001, F(1, N=27)=-2.69)$ and presleep cognitive arousal $(\mathrm{PCA} ; B=0.58, p<.01, F(1$, $N=27)=-2.61$ ) significantly predicted the occurrence of nightmares, while reminiscent stimuli trended towards significance (REMSTEM; $B=0.85, p=.05, F(1, N=27)=-1.88)$. Fixed effect estimates, $95 \%$ confidence intervals, and tests of significance for each predictor are presented in

\section{Table 5.}

\section{Moderation}

In the first step of the logistical moderation analyses, two variables (sleep latency and presleep cognitive arousal) accounted for a significant amount of variance in posttrauma nightmare occurrence, $R^{2}=.09, F(2,27)=7.38, p<.01$. In step two, in order to avoid multicollinearity with the interaction term, sleep latency and presleep cognitive arousal were centered and an interaction term between sleep latency and presleep cognitive arousal was created (Aiken, Reno, \& West, 1991). Lastly, the interaction term was entered into the equation 
and accounted for a significant proportion of the variance in posttrauma nightmare occurrence, $\Delta R^{2}=.25, \Delta F(1,27)=18.89, p=.001, t(27)=1.98, p<.05$. Results of the moderation are reported in Table 6.

\section{Conclusion}

This was the first study to investigate the predictors of posttrauma nightmares in a sample of college women who reported a history of being sexually assaulted. The results suggest that both sleep latency and presleep cognitive arousal were predictors of posttrauma nightmares. These novel findings suggest that both the time it takes to fall asleep and increased negative cognitions before falling asleep may play a pivotal role in the production of posttrauma nightmares. Further investigation of this relationship demonstrated that these predictors were not independent of one another, presleep cognitive arousal significantly moderated the relationship between sleep latency and the occurrence of posttrauma nightmares, suggesting that when cognitive arousal (such as rumination or sleep apprehension) increased the amount of time it took to fall asleep, a posttrauma nightmare was more likely to occur. In summary, the results of this study are the first to empirically support the idea that sleep latency and presleep cognitive arousal both individually and combined may influence the occurrence of a posttrauma nightmare in a sample of college student female sexual assault survivors.

Consistent with extant posttrauma nightmare research, this sample of college-aged women were highly distressed. The PSQI scores were consistently elevated during all nights of the study. However, on nights when nightmares occurred, sleep was profoundly disturbed. Sleep latencies were longer by more than 30 minutes and total sleep time was shorter by more than an hour. Although nightmares are distressing in and of themselves, these data are consistent with prior research showing that it is difficult or impossible to return to sleep following a nightmare 
(Davis, 2008). Although only half of the sample was recruited from a clinical population, almost all study participants reported elevated levels of anxiety and depression symptoms, and all but two met diagnostic criteria for PTSD. Thus, even the portion of the sample that was not obtained by referral may more accurately reflect a clinical population than an average college student population.

The methodology used in this study allowed us to move beyond the study of individual differences and to home in on predictors of nightmares within person and across nights. Although there are a handful of studies that document the prevalence of post trauma nightmares (Germain, 2013), mostly among male combat veterans, none have specifically assessed the antecedents of nightmares on a given night. Because there was little research on the predictors of nightmares, we supplemented predictors derived from models of PTSD with predictors from parasomnia research. Surprisingly, reminiscent stimuli was only marginally significant as a predictor of nightmares, perhaps because reports of reminiscent stimuli were relatively uncommon in this sample of sexual assault survivors. However, nightmares were predicted by the co-occurrence of sleep onset latency and high levels of cognitive arousal. These findings illustrate the importance of trans disciplinary research to inform understanding of basic processes of psychopathology.

\section{Sleep Latency}

Sleep latency was found to significantly predict the occurrence of a posttrauma nightmare. This suggests that increased time spent trying to fall asleep may have been an influential antecedent to the occurrence of a posttrauma nightmare. Although sleep latency was found to be a significant predictor of nightmares, our study was descriptive and based on selfreport, so the precise role of sleep latency in the production of nightmares is unknown. However, 
there are several candidate hypotheses. For instance, it is possible that sleep onset latency is a non-specific marker of psychopathology. Long sleep latency has been found to be a common symptom related to multiple psychopathologies, such as suicidality, depression, \& anxiety (Borbély \& Wirz-Justice, 1982; Papadimitriou \& Linkowski, 2005). However, sleep onset latency was not measured as an individual difference variable in our study, instead it was measured as a level 1 variable, meaning that nightmares were more likely to occur on nights when there was a long sleep onset latency. This may suggest that sleep onset latency is related to the process of nightmare generation rather than a general correlate of psychopathology.

The sleep literature suggests a process level explanation linking sleep onset latency to nightmares. In particular, a long sleep latency may directly influence an individuals' nightly sleep architecture. The inability to fall asleep may lead to increased sleep pressure, which could result in non-REM rebound leading to faster and direct entry to slow wave sleep (SWS; Borbely, \& Neuhaus, 1979; Cajochen, Knoblauch, Kräuchi, Renz, \& Wirz-Justice, 2001). Given that posttrauma nightmares are theorized to occur during SWS (Davis, 2007), it is possible that prolonged sleep latency increases the proportion of SWS, the sleep state during which posttrauma nightmares are thought to occur. Therefore, it is possible that sleep latency is potentiating the occurrence of a posttrauma nightmare by altering an individual's sleep architecture.

Finally, consistent with cognitive models of insomnia, an extended sleep latency may provide an uninterrupted time and space for rumination about traumatic events or concerns that reminiscent stimuli will trigger posttrauma nightmares. This idea is consistent with a large body of research showing that worry, rumination, and sleep anxiety, contribute to difficulty falling asleep (Zoccola, Dickerson, \& Lam, 2009; Gross \& Borkovec, 1982). Following from this 
theoretical model, nightmares and sleep onset insomnia would both be driven by and maintained by anxiety. In the case of insomnia, rumination and worry prevent the onset of sleep. In the case of posttrauma nightmares, anxiety would not only increase arousal, delaying sleep onset, but also provide a period of time free from distractions to process negative cognitions related to a past traumatic experience, setting the stage for the production of a posttrauma nightmares.

\section{Presleep Cognitive Arousal}

Presleep cognitive arousal, reported before bedtime, was found to significantly predict the occurrence of posttrauma nightmares. Similar to measurement of sleep onset latency, the exact mechanism for presleep cognitive arousal in the production of posttrauma nightmares is yet unknown. Because data were collected with a timestamp, we know that presleep cognitive arousal processes were active prior to bedtime. However, our interpretation of the data presupposes that the arousal continued after lights out and during the time while our study participants were trying to fall asleep. The measure of pre-sleep cognitive arousal used in this study includes items such as, how intensely are you worrying about going to sleep and how intensely are you experiencing depressing or anxious thoughts? (Nicassio, Mendlowitz, Fussell, \& Petras, 1985). As shown by these sample items, pre-sleep cognitive arousal overlaps substantially with related constructs worry, presleep anxiety, and rumination. Relatedly, presleep rumination has been found to be a primary contributing factor to insomnia related symptoms in individuals surviving with PTSD (Borders, Rothman, \& McAndrew, 2015). Similarly, worrying or being apprehensive of a stressful stimulus before sleep has been found to significantly negatively impact an individuals sleep quality (Guastella \& Moulds, 2007). Thus, it seems likely that pre-sleep cognitive arousal captured trauma related rumination that began before bedtime, kept participants awake, and resulted in the occurrence of a posttrauma nightmare. 
Another possible explanations as to why presleep cognitive arousal predicted the occurrence of posttrauma nightmares is that the cognitive content captured by presleep cognitive arousal acts as a prime that is later transformed into a posttrauma nightmare. In other words, if an individual reviews or ponders the posttrauma nightmare content before falling asleep, they may be priming the creation of a posttrauma nightmare. This hypothesis, often referred to as the continuity-hypothesis, is supported by a plethora of dream research that hypothesizes that thinking of a stimulus prior to falling asleep makes it more likely for the thought of stimuli to occur in an individuals dream content (Cipolli, Fagioli, Mazzetti, \& Tuozzi, 2004; Riemann, Spiegelhalder, Nissen, Hirscher, Baglioni, \& Feige, 2012). For example, Strauch and Meier (1996) demonstrated that after REM sleep awakenings, participants reported that up to $60 \%$ of their dream content consisted of stimuli experienced prior to falling asleep. Further, Nefjodov et al (2016) conducted a laboratory experiment in which study participants played a balancing video game prior to sleep. Dream content was assessed upon REM sleep awakenings. Although Nefjodov el al (2016) did not capture a large amount of balancing game dreams (5\%), they did find that participants frequently reported that their dreams took place in a laboratory setting (47\%). With the continuity-hypothesis in mind, presleep arousal may significantly predict the occurrence of posttrauma nightmares because presleep cognitions potentially prime the brain to create similar dream content while asleep.

\section{Moderation}

Given that it was unclear which underlying factors of sleep latency and presleep cognitive arousal influenced the occurrence of posttrauma nightmares, this study sought to better understand this relationship by examining the potential interactive effect of presleep cognitive arousal on the relationship between sleep latency and posttrauma nightmare occurrence. Further 
examination of the relationship between, presleep cognitive arousal, sleep latency, and posttrauma nightmare revealed that presleep cognitive arousal significantly moderated the relationship between sleep latency and the occurrence of posttrauma nightmares. This finding suggests that heightened states of cognitive arousal combined with long bouts of sleep latency may create an optimal cognitive environment for the manifestation of a posttrauma nightmare. These specific mechanics are consistent with the continuity-hypothesis which suggests that presleep arousal prevents an individual from falling asleep (Zoccola, Dickerson, \& Lam, 2009), further allowing an opportunity for rumination. One of the methodological strengths of this study was that pre-sleep arousal was reported before bedtime. So, although we cannot infer causality from an observational study, we can be sure of the temporal relationship between pre-sleep cognitive arousal and sleep onset latency. Thus, it appears likely that cognitive arousal may set the stage for a period of extended sleep latency during which rumination/rehearsal of the posttrauma nightmare content may occur, potentially triggering the onset of a posttrauma nightmare.

\section{Limitations \& Future research}

This is the first study utilizing mixed effects methods to attempt to identify night to night predictors of posttrauma nightmares. Thus, there are a number of limitations that limit the generalizability and the precision with which we can interpret our findings. One of the largest limitations of this study was the sample size. A larger sample size would lend more power to the statistical analyses, thus reducing the chance of type- 1 and type- 2 error and allowing us to examine potential differences between the clinical and community sample. Additionally, the study's sample consisted primarily of young female sexual trauma survivors. The results may not be generalizable to other genders, ages, or trauma populations other than sexual traumas. It may 
be the case, for instance, that reminiscent stimuli play a significant role in the triggering of posttrauma nightmares in other populations of trauma survivors, such as combat veterans. Thus, future research should attempt to replicate these results within different trauma survivor populations. The self-report methodology contributed to another limitation given that sleep onset latency is notoriously difficult to self-report accurately. Therefore, the use of actigraphy devices or other portable EEG based sleep measurement tools would have allowed us to determine whether sleep onset latency was objectively longer on posttrauma nightmare nights or whether that nightmares contributed to the perception of a long sleep latency. Despite that there was no significant difference in posttrauma nightmare occurrence rates between referral groups, it should be noted that the clinical group reported significantly higher anxiety and depression symptoms. Thus, the difference in depression and anxiety symptoms could be viewed as a nuisance variable and future research should attempt to utilize more homogenous referral groups. Finally, it is difficult to specify the exact role of pre-sleep cognitive arousal. Future research should examine what specific cognitive arousal variables accounted for the most variance in these predictive results. Specifically, it would be useful to disentangle the roles of pre-sleep worry (about either not being able to fall asleep or the possibility of a posttrauma nightmare) from rumination about posttrauma nightmare related content.

This research illustrates one of the challenges of posttrauma nightmare research. Although participants were selected into the study because they reported frequent posttrauma nightmares, during the course of the study, the majority of participants only reported one posttrauma nightmare, and $18.5 \%$ reported none at all. However, this lack of posttrauma nightmare occurrence is not uncommon. In fact, posttrauma nightmares and other parasomnias are notoriously elusive and often fail to materialize when studied in a laboratory environment. It 
has been suggested that parasomnias may be less likely to occur in laboratory settings, because participants feel a sense of safety while surrounded by researchers (Wittmann, Schredl, \& Kramer, 2007). Thus, the fact that this study captured the occurrence of posttrauma nightmares may indicate that at home assessments of parasomnias may be a more advantageous way to capture their occurrence.

\section{Summary and Clinical Implications}

In summary, our results show that sleep latency and presleep cognitive arousal both individually and jointly influence the occurrence of posttrauma nightmares in a sample of highly distressed female college students who had experienced a sexual trauma. These results are the first of their kind to identify potential triggers of posttrauma nightmares. Aside from the novelty, these results provide meaningful knowledge that can be translated to treatment by suggesting that by treating sleep latency and presleep cognitive arousal, one may indirectly reduce the chance of posttrauma nightmare occurrences. In fact, current posttrauma nightmare treatments, such as exposure, relaxation, and rescripting therapy (ERRT) that successfully decrease rumination and sleep latency has been shown to decrease the frequency in posttrauma nightmare occurrence and PTSD severity (Balliett, Davis, \& Miller, 2015). In conclusion, this study highlighted the meaningful impact of sleep latency and presleep cognitive arousal in regards to the occurrence of a posttrauma nightmare 


\section{References}

Aiken, L. S., West, S. G., \& Reno, R. R. (1991). Multiple regression: Testing and interpreting interactions. Sage.

American Psychiatric Association. (2013). Diagnostic and statistical manual of mental disorders (5th ed.). Washington, DC: Author.

Balliett, N. E., Davis, J. L., \& Miller, K. E. (2015). Efficacy of a brief treatment for nightmares and sleep disturbances for veterans. Psychological trauma: Theory, research, practice, and policy, 7(6), 507.

Beck, A. T., Steer, R. A., \& Brown, G. K. (1996). Beck depression inventory-II. San Antonio, 78(2), 490-8.

Beck, A. T., Epstein, N., Brown, G., \& Steer, R. A. (1988). An inventory for measuring clinical anxiety: psychometric properties. Journal of consulting and clinical psychology, 56(6), 893.

Blevins, C. A., Weathers, F. W., Davis, M. T., Witte, T. K., \& Domino, J. L. (2015). The Posttraumatic Stress Disorder Checklist for DSM-5 (PCL-5): Development and initial psychometric evaluation. Journal of Traumatic Stress, 28, 489-498. doi: $10.1002 /$ jts. 22059

Bonnet, M. H., \& Arand, D. L. (2010). Hyperarousal and insomnia: state of the science. Sleep medicine reviews, 14(1), 9-15.

Borbély, A. A., \& Wirz-Justice, A. (1982). Sleep, sleep deprivation and depression. Hum Neurobiol, 1(205), 10.

Borbely, A. A., \& Neuhaus, H. U. (1979). Sleep-deprivation: effects on sleep and EEG in the rat. Journal of comparative physiology, 133(1), 71-87. 
Borders, A., Rothman, D. J., \& McAndrew, L. M. (2015). Sleep problems may mediate associations between rumination and PTSD and depressive symptoms among OIF/OEF veterans. Psychological Trauma: Theory, Research, Practice, and Policy, 7(1), 76.

Brancu, M., Mann-Wrobel, M., Beckham, J. C., Wagner, H. R., Elliott, A., Robbins, A. T., \& ... Runnals, J. J. (2016). Subthreshold posttraumatic stress disorder: A meta-analytic review of DSM-IV prevalence and a proposed DSM-5 approach to measurement. Psychological Trauma: Theory, Research, Practice, and Policy, 8(2), 222-232. doi:10.1037/tra0000078

Buysse, D. J., Reynolds, C. F., Monk, T. H., Berman, S. R., \& Kupfer, D. J. (1989). The Pittsburgh Sleep Quality Index: a new instrument for psychiatric practice and research. Psychiatry research, 28(2), 193-213.

Cajochen, C., Knoblauch, V., Kräuchi, K., Renz, C., \& Wirz-Justice, A. (2001). Dynamics of frontal EEG activity, sleepiness and body temperature under high and low sleep pressure. Neuroreport, 12(10), 2277-2281.

Campbell, D. G., Felker, B. L., Liu, C. F., Yano, E. M., Kirchner, J. E., Chan, D., ... \& Chaney, E. F. (2007). Prevalence of depression-PTSD comorbidity: Implications for clinical practice guidelines and primary care-based interventions. Journal of General Internal Medicine, 22(6), 711-718.

Carpenter, J. S., \& Andrykowski, M. A. (1998). Psychometric evaluation of the Pittsburgh sleep quality index. Journal of psychosomatic research, 45(1), 5-13.

Center for Substance Abuse Treatment. (2014). Trauma-Informed Care in Behavioral Health Services. 
Cipolli, C., Fagioli, I., Mazzetti, M., \& Tuozzi, G. (2004). Incorporation of presleep stimuli into dream contents: evidence for a consolidation effect on declarative knowledge during REM sleep. Journal of sleep research, 13(4), 317-326.

Cohen, S., Kamarck, T., \& Mermelstein, R. (1983). A global measure of perceived stress. Journal of health and social behavior, 385-396.

Davis, J. L., Wright, D. C., \& Borntrager, C. (2001). The Trauma-Related Nightmare Scale. Tulsa, OK: University of Tulsa.

Davis, J. L. (2008). Treating post-trauma nightmares: A cognitive behavioral approach. Springer Publishing Company.

Davis, J. L., \& Wright, D. C. (2007). Randomized clinical trial for treatment of chronic nightmares in trauma-exposed adults. Journal of Traumatic Stress, 20(2), 123-133.

Ehlers, A., Hackmann, A., \& Michael, T. (2004). Intrusive re-experiencing in post-traumatic stress disorder: Phenomenology, theory, and therapy. Memory, 12(4), 403-415.

Ehring, T., Frank, S., \& Ehlers, A. (2008). The role of rumination and reduced concreteness in the maintenance of posttraumatic stress disorder and depression following trauma. Cognitive therapy and research, 32(4), 488-506.

Faraway, J. J. (2016). Extending the linear model with R: generalized linear, mixed effects and nonparametric regression models (Vol. 124). CRC press.

Faul, F., Erdfelder, E., Lang, A. G., \& Buchner, A. (2007). G* Power 3: A flexible statistical power analysis program for the social, behavioral, and biomedical sciences. Behavior research methods, 39(2), 175-191.

Fedina, L., Holmes, J. L., \& Backes, B. L. (2018). Campus sexual assault: A systematic review of prevalence research from 2000 to 2015. Trauma, violence, \& abuse, 19(1), 76-93. 
Feldman, L. A. (1995). Valence focus and arousal focus: Individual differences in the structure of affective experience. Journal of personality and social psychology, 69(1), 153.

First, M. B., Williams, J. B. W., Karg, R. S., \& Spitzer, R. (2015). Structured clinical interview for DMS-5, Research Version. Arlington, VA: American Psychiatric Association.

Forbes, D., Phelps, A.,\&McHugh, T. (2001). Treatment of combat related nightmares using imagery rehearsal: A Pilot Study. Journal of Traumatic Stress, 14, 433-442.

Fydrich, T., Dowdall, D., \& Chambless, D. L. (1992). Reliability and validity of the Beck Anxiety Inventory. Journal of anxiety disorders, 6(1), 55-61.

Galatzer-Levy, I. R., Nickerson, A., Litz, B. T., \& Marmar, C. R. (2013). Patterns of lifetime PTSD comorbidity: A latent class analysis. Depression and Anxiety, 30(5), 489-496.

Germain, A., Hall, M., Krakow, B., Shear, M. K., \& Buysse, D. J. (2005). A brief sleep scale for posttraumatic stress disorder: Pittsburgh Sleep Quality Index Addendum for PTSD. Journal of anxiety disorders, 19(2), 233-244.

Germain, A. (2013). Sleep disturbances as the hallmark of PTSD: where are we now. American Journal of Psychiatry, 170(4), 372-382.

Gradus, J. L. (2007). Epidemiology of PTSD. National Center for PTSD (United States Department of Veterans Affairs).

Gross, R. T., \& Borkovec, T. D. (1982). Effects of a cognitive intrusion manipulation on the sleep-onset latency of good sleepers. Behavior Therapy, 13(1), 112-116.

Gregory, A. M., Willis, T. A., Wiggs, L., Harvey, A. G., \& STEPS team. (2008). Presleep arousal and sleep disturbances in children. Sleep, 31(12), 1745-1747.

Guastella, A. J., \& Moulds, M. L. (2007). The impact of rumination on sleep quality following a stressful life event. Personality and Individual Differences, 42(6), 1151-1162. 
Hartmann, E. (1984). The nightmare: The psychology and biology of terrifying dreams. Basic Books (AZ).

Hartmann, E. (1998). Dreams and nightmares: The new theory on the origin and meaning of dreams. Plenum Trade.

Hayes, A.F. (2012). PROCESS: A versatile computational tool for observed variables mediation, Moderation, and conditional processing.

Hiestand, D. M., Britz, P., Goldman, M., \& Phillips, B. (2006). Prevalence of symptoms and risk of sleep apnea in the US population: results from the national sleep foundation sleep in America 2005 poll. CHEST Journal, 130(3), 780-786.

Jakupcak, M., Hoerster, K. D., Varra, A., Vannoy, S., Felker, B., \& Hunt, S. (2011).

Hopelessness and suicidal ideation in Iraq and Afghanistan war veterans reporting subthreshold and threshold posttraumatic stress disorder. The Journal of nervous and mental disease, 199(4), 272-275.

Kerkhof, G. A., \& Van Dongen, H. P. A. (2010). Effects of sleep deprivation on cognition. Human Sleep and Cognition: Basic Research, 185, 105.

Kilpatrick, D. G., Ruggiero, K. J., Acierno, R., Saunders, B. E., Resnick, H. S., \& Best, C. L. (2003). Violence and risk of PTSD, major depression, substance abuse/dependence, and comorbidity: results from the National Survey of Adolescents. Journal of consulting and clinical psychology, 71(4), 692.

Kilpatrick, D. G., Resnick, H. S., Milanak, M. E., Miller, M. W., Keyes, K. M., \& Friedman, M. J. (2013). National estimates of exposure to traumatic events and PTSD prevalence using DSM-IV and DSM-5 criteria. Journal of traumatic stress, 26(5), 537-547. 
Krakow, B., Hollifield, M., Johnston, L., Koss, M., Schrader, R., Warner, T. D., ... \& Cheng, D. (2001). Imagery rehearsal therapy for chronic nightmares in sexual assault survivors with posttraumatic stress disorder: a randomized controlled trial. Jama, 286(5), 537-545.

Krebs, C. P., Lindquist, C. H., Warner, T. D., Fisher, B. S., \& Martin, S. L. (2009). College women's experiences with physically forced, alcohol-or other drug-enabled, and drugfacilitated sexual assault before and since entering college. Journal of American College Health, 57(6), 639-649.

Lamarche, L. J., \& De Koninck, J. (2007). Sleep disturbance in adults with posttraumatic stress disorder: a review. The Journal of clinical psychiatry.

Levin, R., \& Nielsen, T. A. (2007). Disturbed dreaming, posttraumatic stress disorder, and affect distress: a review and neurocognitive model. Psychological bulletin, 133(3), 482.

Michael, T., Ehlers, A., Halligan, S. L., \& Clark, D. M. (2005). Unwanted memories of assault: what intrusion characteristics are associated with PTSD. Behavior research and therapy, 43(5), 613-628.

Michielsen, H. J., De Vries, J., \& Van Heck, G. L. (2003). Psychometric qualities of a brief selfrated fatigue measure: The Fatigue Assessment Scale. Journal of psychosomatic research, 54(4), 345-352.

Morrison, A. R. (1989). Sleep disturbance as the hallmark of posttraumatic stress disorder. American Journal of Psychiatry, 146(6), 697-707.

Nadorff, M., Nazem, S., \& Fiske, A. (2013). Insomnia symptoms, nightmares, and suicide risk: duration of sleep disturbance matters. Suicide and Life-Threatening Behavior, 43(2), 139149. 
Nefjodov, I., Winkler, A., \& Erlacher, D. (2016). Balancing in dreams: Effects of playing games on the Wii balance board on dream content. International Journal of dream research, 9(1), 89-92.

Nicassio, P. M., Mendlowitz, D. R., Fussell, J. J., \& Petras, L. (1985). The phenomenology of the pre-sleep state: the development of the pre-sleep arousal scale. Behaviour research and therapy, 23(3), 263-271.

Ohayon, M. M., \& Shapiro, C. M. (2000). Sleep disturbances in psychiatric disorders associated with posttraumatic stress disorder in the general population. Comprehensive Psychiatry, $41,469-478$.

Pacella, M. L., Hruska, B., \& Delahanty, D. L. (2013). The physical health consequences of PTSD and PTSD symptoms: a meta-analytic review. Journal of Anxiety Disorders, 27(1), $33-46$.

Papadimitriou, G. N., \& Linkowski, P. (2005). Sleep disturbance in anxiety disorders. International review of psychiatry, 17(4), 229-236.

Pruiksma, K. E., Taylor, D. J., Wachen, J. S., Mintz, J., Young-McCaughan, S., Peterson, A. L., \& Resick, P.A. (2016). Residual sleep disturbances following ptsd treatment in active duty military personnel. Psychological Trauma: Theory, Research, Practice and Policy, $8(6), 697-701$

Rechtschaffen, A., Bergmann, B. M., Gilliland, M. A., \& Bauer, K. (1999). Effects of method, duration, and sleep stage on rebounds from sleep deprivation in the rat. SLEEP-NEW YORK-, 22, 11-32.

Riemann, D., Spiegelhalder, K., Nissen, C., Hirscher, V., Baglioni, C., \& Feige, B. (2012). REM sleep instability-a new pathway for insomnia. Pharmacopsychiatry, 45(05), 167-176. 
Roehrs, T., Hyde, M., Blaisdell, B., Greenwald, M., \& Roth, T. (2006). Sleep loss and REM sleep loss are hyperalgesic. Sleep-New York Then Westchester-, 29(2), 145.

Raskind, M. A., Peskind, E. R., Kanter, E. D., Petrie, E. C., Radant, A., Thompson, C. E., ... \& Thomas, R. G. (2003). Reduction of nightmares and other PTSD symptoms in combat veterans by prazosin: a placebo-controlled study. American Journal of Psychiatry, 160(2), 371-373.

Rothbaum, B. O., Foa, E. B., Riggs, D. S., Murdock, T., \& Walsh, W. (1992). A prospective examination of post-traumatic stress disorder in rape victims. Journal of Traumatic stress, 5(3), 455-475.

Ross, R. J., Ball, W. A., Sullivan, K. A., \& Caroff, S. N. (1989). Sleep disturbance as the hallmark of posttraumatic stress disorder. The American journal of psychiatry, 146(6), 697.

Schneider, A., \& Domhoff, G. W. (2001). Quantitative Study of Dreams. University of California, Santa Cruz.

Schredl, M. (2015). The Continuity Between Waking And Dreaming. Dream Research: Contributions to Clinical Practice, 27.

Seedat, S., Stein, M. B., \& Forde, D. R. (2005). Association between physical partner violence, posttraumatic stress, childhood trauma, and suicide attempts in a community sample of women. Violence and victims, 20(1), 87-98.

Smith, M. T., Perlis, M. L., Carmody, T. P., Smith, M. S., \& Giles, D. E. (2001). Presleep cognitions in patients with insomnia secondary to chronic pain. Journal of Behavioral Medicine, 24(1), 93-114. 
Spoormaker, V. I., Schredl, M., \& van den Bout, J. (2006). Nightmares: from anxiety symptom to sleep disorder. Sleep medicine reviews, 10(1), 19-31.

Spoormaker, V. I., \& Montgomery, P. (2008). Disturbed sleep in post-traumatic stress disorder: secondary symptom or core feature?. Sleep medicine reviews, 12(3), 169-184.

Stickgold, R., Hobson, J. A., Fosse, R., \& Fosse, M. (2001). Sleep, learning, and dreams: off-line memory reprocessing. Science, 294(5544), 1052-1057.

Strauch, I., \& Meier, B. (1996). In search of dreams: Results of experimental dream research. SUNY Press.

Thayer, R. E. (1990). The biopsychology of mood and arousal. Oxford University Press.

U.S. Department of Education, National Center for Education Statistics, Common Core of Data (CCD), "State Nonfiscal Survey of Public Elementary and Secondary Education," 199091 through 2013-14; Private School Universe Survey (PSS), 1995-96 through 2013-14; National Elementary and Secondary Enrollment Projection Model, 1972 through 2025; Integrated Postsecondary Education Data System (IPEDS), "Fall Enrollment Survey" (IPEDS-EF:90-99); IPEDS Spring 2001 through Spring 2015, Fall Enrollment component; and Enrollment in Degree-Granting Institutions Projection Model, 1980 through 2025. (This table was prepared February 2016.)

Van der Kolk, B., Blitz, R., Burr, W., Sherry, S., \& Hartmann, E. (1984). Nightmares and trauma: A comparison of nightmares after combat with lifelong nightmares in veterans. American Journal of Psychiatry, 141(2), 187-190.

Wang, Y. P., \& Gorenstein, C. (2013). Psychometric properties of the Beck Depression Inventory-II: a comprehensive review. Revista Brasileira de Psiquiatria, 35(4), 416-431. 
Weathers, F.W., Litz, B.T., Keane, T.M., Palmieri, P.A., Marx, B.P., \& Schnurr, P.P. (2013). The PTSD Checklist for DSM-5 (PCL-5).

Wicklow, A., \& Espie, C. A. (2000). Intrusive thoughts and their relationship to actigraphic measurement of sleep: towards a cognitive model of insomnia. Behaviour research and therapy, 38(7), 679-693.

Wittmann, L., Schredl, M., \& Kramer, M. (2007). Dreaming in posttraumatic stress disorder: A critical review of phenomenology, psychophysiology and treatment. Psychotherapy and psychosomatics, 76(1), 25-39.

Zoccola, P. M., Dickerson, S. S., \& Lam, S. (2009). Rumination predicts longer sleep onset latency after an acute psychosocial stressor. Psychosomatic Medicine, 71(7), 771-775. 
Table 1

Predictor Descriptives

\begin{tabular}{|c|c|c|c|c|c|c|}
\hline & \multicolumn{2}{|l|}{ POTEC } & \multicolumn{2}{|c|}{ Clinical } & \multicolumn{2}{|c|}{ Combined } \\
\hline & $M(S D)$ & Mode & $M(S D)$ & Mode & $M(S D)$ & Mode \\
\hline $\begin{array}{l}\text { Reminiscent } \\
\text { Stimuli }\end{array}$ & $.23(.43) * *$ & 0.0 & $.46(.50) * *$ & 0.0 & $.37(.48)$ & 0.0 \\
\hline Fatigue & $2.23(1.85)^{*}$ & 2.0 & $3.81(2.43)^{*}$ & 2.0 & $3.16(2.34)$ & 2.0 \\
\hline Stress & $7.65(1.65)$ & 8.0 & $7.78(1.96)$ & 6.0 & $7.73(1.84)$ & 8.0 \\
\hline $\begin{array}{l}\text { Presleep } \\
\text { Cognitive } \\
\text { Arousal }\end{array}$ & $13.72(8.74)$ & 9.0 & 13.09(6.93) & 17.0 & $13.35(7.71)$ & 6.0 \\
\hline $\begin{array}{l}\text { Presleep } \\
\text { Somatic } \\
\text { Arousal }\end{array}$ & $4.03(2.93)$ & 2.0 & $6.10(4.17)$ & 5.0 & $5.25(3.83)$ & 3.0 \\
\hline PSQI Scales & & & & & & \\
\hline $\begin{array}{l}\text { Global } \\
\text { Sleep } \\
\text { Quality }\end{array}$ & $6.95(3.65)$ & 4.0 & $9.12(3.59)$ & 7.0 & $8.16(3.76)$ & 5.0 \\
\hline $\begin{array}{l}\text { Subjective } \\
\text { Sleep } \\
\text { Quality }\end{array}$ & $1.35(.80)$ & 1.0 & $1.41(.69)$ & 1.0 & $1.38(.74)$ & 1 \\
\hline $\begin{array}{l}\text { Sleep } \\
\text { Efficiency }\end{array}$ & $1.38(.84)$ & 1.0 & $1.33(.77)$ & 1.0 & $1.35(.79)$ & 1.0 \\
\hline $\begin{array}{l}\text { Daytime } \\
\text { Dysfunction }\end{array}$ & $1.65(1.32) * *$ & 2.0 & $2.89(1.65)^{* *}$ & 3.0 & $2.38(1.64)$ & 2.0 \\
\hline $\begin{array}{l}\text { Sleep } \\
\text { Duration }\end{array}$ & $.63(1.01)$ & 0.0 & $.88(.70)$ & 1.0 & $.77(.99)$ & 0 \\
\hline $\begin{array}{l}\text { Sleep } \\
\text { Latency }\end{array}$ & $1.43(.85)$ & 1.0 & $1.32(.76)$ & 1.0 & $1.37(.79)$ & 1 \\
\hline
\end{tabular}


Table 2

Demographics

\begin{tabular}{|c|c|c|c|}
\hline & POTEC $(N=12)$ & Clinical $(N=15)$ & Combined $(N=27)$ \\
\hline Past Traumas & $58.33 \%(n=7)$ & $53.33 \%(n=8)$ & $55.55 \%(n=15)$ \\
\hline $\begin{array}{l}\text { Past Sexual } \\
\text { Trauma }\end{array}$ & $41.67 \%(n=5)$ & $53.33 \%(n=8)$ & $51.85 \%(n=13)$ \\
\hline PTSD & $91.67 \%(n=11)$ & $93.33 \%(n=14)$ & $92.60(n=25)$ \\
\hline \multicolumn{4}{|l|}{ Ethnicity } \\
\hline White & $91.67 \%(n=11)$ & $33.33 \%(n=5)$ & $59.26 \%(n=16)$ \\
\hline Hispanic & $8.33 \%(n=1)$ & $33.33 \%(n=5)$ & $18.52 \%(n=6)$ \\
\hline Asian & $0 \%$ & $20 \%(n=3)$ & $11.11 \%(n=3)$ \\
\hline African & $0 \%$ & $13.33 \%(n=2)$ & $7.41 \%(n=2)$ \\
\hline \multicolumn{4}{|l|}{$\underline{\text { SES }}$} \\
\hline$<30 \mathrm{k}$ & $16.67 \%(n=2)$ & $20 \%(n=3)$ & $18.52 \%(n=5)$ \\
\hline $30-75 k$ & $50 \%(n=6)$ & $20 \%(n=3)$ & $37.03 \%(n=9)$ \\
\hline $75-100 \mathrm{k}$ & $16.67 \%(n=2)$ & $40 \%(n=6)$ & $25.93 \%(n=8)$ \\
\hline $100 \mathrm{k}+$ & $16.67 \%(n=2)$ & $20 \%(n=3)$ & $18.52 \%(n=5)$ \\
\hline Age & $\begin{array}{c}M 20.14 \\
(S D=1.35)\end{array}$ & $\begin{array}{c}M=22.44 \\
(S D=3.71)\end{array}$ & $\begin{array}{c}M=21.44 \\
(S D=3.08)\end{array}$ \\
\hline $\begin{array}{l}\text { Age at } \\
\text { Trauma }\end{array}$ & $\begin{array}{l}M=16.86^{*} \\
(S D=2.11)\end{array}$ & $\begin{array}{l}M=19.55^{*} \\
(S D=3.57)\end{array}$ & $\begin{array}{c}M=18.38 \\
(S D=3.24)\end{array}$ \\
\hline $\begin{array}{l}\text { Years Since } \\
\text { Trauma }\end{array}$ & $\begin{array}{c}M=3.28 \\
(S D=1.98)\end{array}$ & $\begin{array}{c}M=2.89 \\
(S D=1.36)\end{array}$ & $\begin{array}{c}M=3.06 \\
(S D=1.61)\end{array}$ \\
\hline BAI & $\begin{array}{l}M=23.71 * \\
(S D=8.42)\end{array}$ & $\begin{array}{c}M=31.33^{*} \\
(S D=12.11)\end{array}$ & $\begin{array}{c}M=28.00 \\
(S D=11.04)\end{array}$ \\
\hline BDI & $\begin{array}{l}M=16.57^{*} \\
(S D=7.39)\end{array}$ & $\begin{array}{l}M=21.22 * \\
(S D=4.82)\end{array}$ & $\begin{array}{c}M=19.19 \\
(S D=6.31)\end{array}$ \\
\hline
\end{tabular}

Note: $N=27 ; *=p<0.05$ 
Table 3

Internal Consistency Reliability

\begin{tabular}{|c|c|}
\hline Measure & $\alpha$ \\
\hline Fatigue & 0.92 \\
\hline Perceived Stress & 0.75 \\
\hline PSQI & 0.64 \\
\hline Presleep Arousal & 0.82 \\
\hline Cognitive Arousal & 0.92 \\
\hline Somatic Arousal & 0.68 \\
\hline
\end{tabular}


Table $4 \mathrm{a}$

Predictors Stratified by Posttrauma Nightmare Occurrence, t-tests

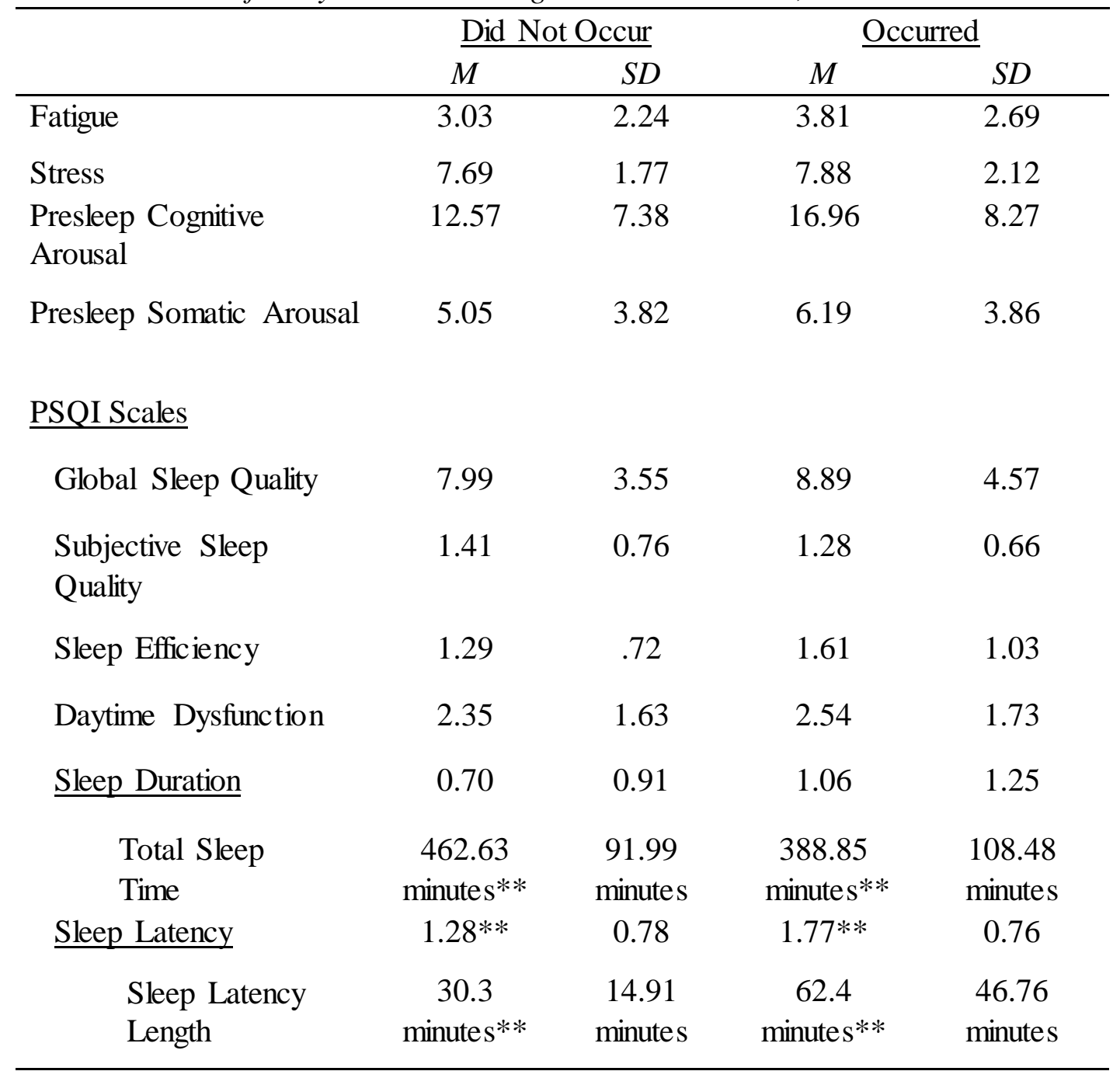

Note: $N=27 ; *=p<0.05, * *=p<0.01$ 
Table $4 \mathrm{~b}$

Predictors Stratified by Posttrauma Nightmare Occurrence, Chi-Square

\begin{tabular}{lccccc}
\hline & \multicolumn{2}{c}{ Nights without } & nightmare & & \multicolumn{2}{c}{ Nights with nightmares } \\
\cline { 2 - 3 } & Yes $(\%)$ & No $(\%)$ & & Yes $(\%)$ & No $(\%)$ \\
\hline $\begin{array}{l}\text { Reminiscent } \\
\text { Stimuli } \\
\text { Experienced }\end{array}$ & $40(33.33 \%)$ & $\begin{array}{c}80 \\
(66.67 \%)\end{array}$ & & $17(56.67 \%)^{*}$ & $13(43.33 \%)$ \\
\hline
\end{tabular}

Note: $N=27 ; *=p<0.05$ 
Table 5

Mixed Effects Logistic Regression Predictor Results

\begin{tabular}{|c|c|c|c|c|}
\hline Predictor & $\begin{array}{l}\text { Unstandardized } \\
\beta \text { Coefficient }\end{array}$ & $S E$ & $p$ & $95 \% \mathrm{CI}$ \\
\hline Reminiscent Stimuli & 0.85 & 0.44 & $0.05 *$ & 0.99 to 5.59 \\
\hline Fatigue & 0.14 & 0.09 & 0.13 & 0.96 to 1.37 \\
\hline Perceived Stress & 0.06 & 0.12 & 0.63 & 0.84 to 1.33 \\
\hline Presleep Cognitive Arousal & 0.58 & 0.23 & $0.01 *$ & 1.15 to 2.84 \\
\hline Presleep Somatic Arousal & 0.56 & 0.42 & 0.17 & 0.76 to 4.04 \\
\hline \multicolumn{5}{|l|}{$\underline{\text { PSQI Scales }}$} \\
\hline Global Sleep Quality & 0.06 & 0.91 & 0.36 & 0.93 to 1.23 \\
\hline Subjective Sleep Quality & -0.25 & -0.68 & 0.49 & 0.37 to 1.57 \\
\hline Sleep Latency & 0.76 & 0.28 & $0.00 * *$ & 0.02 to 0.17 \\
\hline Sleep Efficiency & 0.51 & 0.33 & 0.12 & 0.87 to 3.26 \\
\hline Daytime Dysfunction & 0.05 & 0.33 & 0.74 & 0.78 to 1.39 \\
\hline Sleep Duration & 0.34 & 1.36 & 0.17 & 0.84 to 2.29 \\
\hline
\end{tabular}

Note: $N=27, *=p>.05, * *=p>.01$ 
Table 6

Moderation Results

\begin{tabular}{lccccc}
\hline & $\begin{array}{c}\text { Unstandardized } \beta \\
\text { Coefficient }\end{array}$ & $S E$ & $p$ & LLCI & ULCI \\
\hline Presleep Cognitive Arousal (PCA) & 0.56 & 0.31 & 0.07 & -0.00 & 0.12 \\
Sleep Latency (SL) & 0.60 & 0.31 & 0.05 & -0.01 & 1.21 \\
PCA_SL & 0.08 & 0.42 & $0.04^{*}$ & 0.00 & 0.16 \\
\hline
\end{tabular}

Note: $N=27, *=p>.05$ 
Figure 1

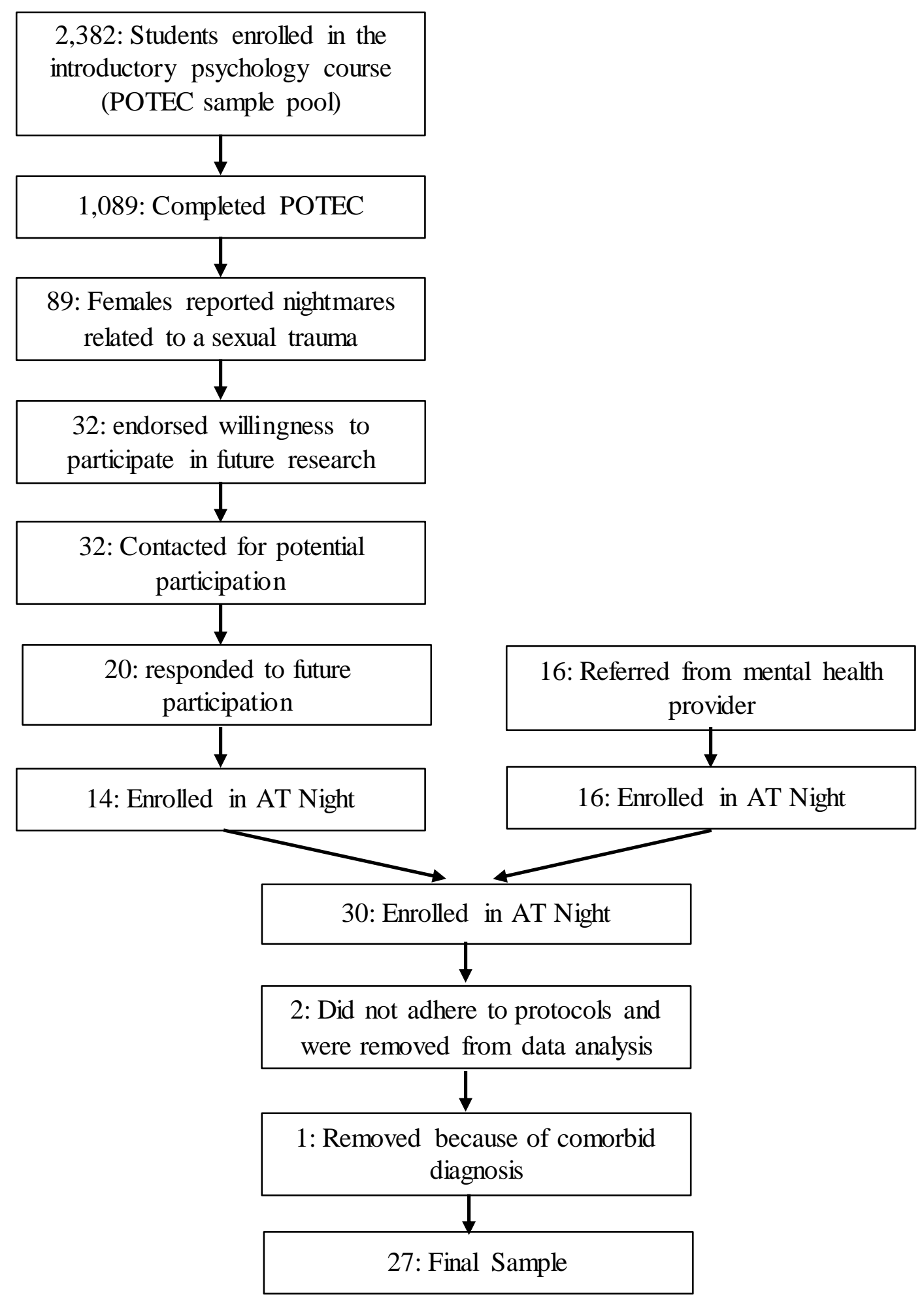

